Fixed Point Theory, 22(2021), No. 2, 809-836

DOI: $10.24193 /$ fpt-ro.2021.2.53

http://www.math.ubbcluj.ro/ nodeacj/sfptcj.html

\title{
A NEW PARALLEL ALGORITHM TO SOLVING A SYSTEM OF QUASI-VARIATIONAL INCLUSION PROBLEMS AND COMMON FIXED POINT PROBLEMS IN BANACH SPACES
}

\author{
JENWIT PUANGPEE* AND SUTHEP SUANTAI** \\ *PhD Degree Program in Mathematics, Faculty of Science, \\ Chiang Mai University, Chiang Mai 50200, Thailand \\ E-mail: jenwit.pp@hotmail.com \\ ** Data Science Research Center, \\ Department of Mathematics, Faculty of Science, Chiang Mai University, \\ Chiang Mai 50200, Thailand \\ E-mail: suthep.s@cmu.ac.th
}

\begin{abstract}
In this paper, a new parallel algorithm for finding a common solution of a system of quasi-variational inclusion problems and a common fixed point of a finite family of nonexpansive mappings in a q-uniformly Banach space is introduced and analyzed. A strong convergence theorem of the proposed algorithm is established under some control conditions. As a consequence, we apply our main results to solve convex minimization problems, multiple sets variational inequality problems and multiple sets equilibrium problems. Some numerical experiments of image restoration problems are also given for supporting the main results.

Key Words and Phrases: Maximal monotone operator, inverse strong accretive operator, variational inclusion problem, Banach space, strong convergence.
\end{abstract}

2020 Mathematics Subject Classification: 47H09, 47H10, 47H17.

Acknowledgment. The authors would like to thank Chiang Mai University, Chiang Mai, Thailand for the financial support.

\section{REFERENCES}

[1] J.B. Baillon, G. Haddad, Quelques proprietes des operateurs angle-bornes et cycliquement monotones, Isr. J. Math., 26(1977), no. 2, 137-150.

[2] V. Barbu, Nonlinear Semigroups and Differential Equations in Banach Spaces, Noordhoff, Leiden, 1976.

[3] D.P. Bertsekas, J.N. Tsitsiklis, Parallel and Distributed Computation: Numerical Methods, Athena Scientific, Belmont, 1997.

[4] E. Blum, W. Oettli, From optimization and variational inequalities to equilibrium problems, Math. Stud., 63(1944), 123-145.

[5] H. Brézis, P.L. Lions, Produits infinis de resolvantes, Israel J. Math., 29(1978), 329-345.

[6] F.E. Browder, Fixed-point theorems for noncompact mappings in Hilbert space, Proc. Natl. Acad. Sci. USA., 53(1965), 1272-1276. 
[7] C. Byrne, A unified treatment of some iterative algorithms in signal processing and image reconstruction, Inverse Probl., 20(2004), no. 1, 103-120.

[8] G.H.G. Chen, R.T. Rockafellar, Convergence rates in forward-backward splitting, SIAM J. Optim., 7(1997), 421-444.

[9] C. Chidume, Geometric Properties of Banach Spaces and Nonlinear Iterations, Springer, London, 2009.

[10] P.L. Combettes, The Convex Feasibility Problem in Image Recovery, In: Hawkes, P. (ed.), Advances in Imaging and Electron Physics, Academic Press, New York, 1996.

[11] P.L. Combettes, S.A. Hirstoaga, Equilibrium programming in Hilbert spaces, J. Nonlinear Convex Anal., 6(2005), 117-136.

[12] P.L. Combettes, V.R. Wajs, Signal recovery by proximal forward-backward splitting, Multiscale Model Simul., 4(2005), 1168-1200.

[13] J.C. Dunn, Convexity, monotonicity, and gradient processes in Hilbert space, J. Math. Anal Appl., 53(1976), 145-158.

[14] F. Facchinei, J.S. Pang, Finite-Dimensional Variational Inequalities and Complementarity Problems, Springer, New York, 2003.

[15] O. Güler, On the convergence of the proximal point algorithm for convex minimization, SIAM J. Control Optim., 29(1991), 403-419.

[16] S. Kamimura, W. Takahashi, Approximating solutions of maximal monotone operators in Hilbert spaces, J. Approx. Theory, 106(2000), no. 2, 226-240.

[17] W. Khuangsatung, A. Kangtunyakarn, Strong convergence theorems for the modified variational inclusion problems and various nonlinear mappings in Hilbert space, J. Math. Anal. Appl., Special Issue (ACFPTO 2016), 125-152.

[18] D. Kinderlehrer, G. Stampacchia, An Introduction to Variational Inequalities and Their Applications, Academic Press, New York, 1980.

[19] W. Li, A new iterative algorithm with errors for maximal monotone operators and its applications, Mach. Learn. Cybern., 2(2005), 18-21.

[20] P.L. Lions, B. Mercier, Splitting algorithms for the sum of two nonlinear operators, SIAM J. Numer. Anal., 16(1979), 964-979.

[21] G. Lopez, V. Martin-Marquez, F. Wang, H.K. Xu, Forward-backward splitting methods for accretive operators in Banach spaces, Abstr. Appl. Anal., 2012(2012), 25 pages.

[22] B. Martinet, Régularisation d'inéquations variationnelles par approximations successives, Rev. Française Informat. Recherche. Opérationnelle, 4(1970), 154-158.

[23] D.S. Mitrinović, Analytic Inequalities, Springer, New York, 1970.

[24] N. Parikh, S. Boyd, Proximal Algorithms, Foundations and Trends ${ }^{\circledR}$ in Optimization, 1(2014), no. 3, 127-239.

[25] G.B. Passty, Ergodic convergence to a zero of the sum of monotone operators in Hilbert space, J. Math. Anal. Appl., 72(1979), 383-390.

[26] R.T. Rockafellar, On the maximal monotonicity of subdifferential mappings, Pac. J. Math., 33(1970), 209-216.

[27] R.T. Rockafellar, Monotone operators and the proximal point algorithm, SIAM J. Control Optim., 14(1976), 877-898.

[28] S. Suantai, P. Cholamjiak, P. Sunthrayuth, Iterative methods with perturbations for the sum of two accretive operators in q-uniformly smooth Banach spaces, RACSAM, 113(2019), 203-223.

[29] T. Suzuki, Strong convergence of Krasnoselskii and Mann's type sequence for one-parameter nonexpansive semigroup without Bochner integrals, J. Math. Anal. Appl., 305(2005), 227-239.

[30] S. Takahashi, W. Takahashi, M. Toyoda, Strong convergence theorems for maximal monotone operators with nonlinear mappings in Hilbert spaces, J. Optim. Theory Appl., 147(2010), no. $1,27-41$.

[31] W. Takahashi, Convex Analysis and Approximation of Fixed Points, (Japanese), Yokohama Publishers, Yokohama, 2000.

[32] K.-H. Thung, P. Raveendran, A Survey of Image Quality Measures, IEEE Technical Postgraduates (TECHPOS) International Conference, Kuala Lumpur, 14-15 December 2009, 1-4. 
[33] P. Tseng, A modified forward-backward splitting method for maximal monotone mappings, SIAM J. Control Optim., 38(2000), 431-446.

[34] H.K. Xu, Inequalities in Banach spaces with applications, Nonlinear Anal. Theory Methods Appl., 16(1991), 1127-1138.

[35] H.K. Xu, Iterative algorithms for nonlinear operators, J. London Math. Soc., 66(2002), no. 1, 240-256.

[36] Y. Yao, Y.J. Cho, Y.-C. Liou, Algorithms of common solutions for variational inclusions, mixed equilibrium problems and fixed point problems, Eur. J. Oper. Res., 212(2011), no. 2, 242-250.

[37] H.T. Zegeye, N. Shahzad, Strong convergence theorems for a common zero for a finite family of m-accretive mappings, Nonlinear Anal., 66(2007), 1161-1169.

[38] S.S. Zhang, J.H.W. Lee, C.K. Chan, Algorithms of common solutions for quasi-variational inclusion and fixed point problems, Appl. Math. Mech., 29(2008), 571-581.

Received: March 7, 2019; Accepted: May 16, 2020. 
